\title{
The use of electrical impedance tomography to the differential diagnosis of pathological mammographic/sonographic findings
}

\author{
O. RANETA ${ }^{1, *}$, V. BELLA ${ }^{2}$, L. BELLOVA ${ }^{2}$, E. ZAMECNIKOVA ${ }^{2}$ \\ ${ }^{1} 1$ st Department of Oncology, Comenius University Faculty of Medicine, Bratislava, Slovak Republic; ${ }^{2}$ St. Elisabeth Cancer Institute, Bratislava, \\ Slovak Republic
}

*Correspondence: olga_raneta@hotmail.com

Received November 17, 2012 / Accepted March 19, 2013

\begin{abstract}
Our study involved 870 eligible women with suspected pathological breast lesion discovered by mammography (MMG) or ultrasound examination (USG) which were recommended to pass histological examination to verify the diagnosis. All patients included in our study were divided into two age groups: the $1^{\text {st }}$ group - patients older than 40 years (total of 724 patients), the $2^{\text {nd }}$ group - patients younger than 40 years (total of 146 patients). The purpose of our study was to analyze the possibilities of electrical impedance tomography (EIT) implementation to the differential diagnosis of pathologic lesions of the breast either solely, or in a combination with MMG/USG.

The following results were obtained: in the $1^{\text {st }}$ group the average specificity of MMG was $79.5 \%$; when added EIT the average specificity decreased to $72.8 \%$. The sensitivity of MMG, by contrast, increased from $87.8 \%$ when using it as an independent method to $94.5 \%$ when added EIT.

In the $2^{\text {nd }}$ group the average specificity of USG was $90.2 \%$; when added EIT the average specificity decreased to $86.4 \%$. Similarly, as in the $1^{\text {st }}$ group the sensitivity of USG increased from $86.7 \%$ when using it as an independent method to $93.3 \%$ when added EIT.

Analysis of false-negative results of electrical impedance tomography depending on the stage of the process has shown that as the earlier stage of the disease and as the smaller is the dimensions of the tumor, the higher is the number of falsenegative results. In addition, we observed the dependence of the false-negative results of the tumor grade. The results of our study show that the use of EIT in addition to MMG/USG can improve the sensitivity of these methods and to increase the rate of early detection of breast cancer with minimal economic costs and highly qualified staff time expenditures.
\end{abstract}

Key words: sensitivity, specificity, electrical impedance tomography, breast disease, diagnostics

Currently the early diagnosis of breast cancer represents one of the most pressing problems. Breast cancer occupies the first place in the range of the causes of death in the female population in a great number of countries $[1,2]$.

Specialists mention that the early stage of the tumor according to clinical indications is considered as the "late" one from the biological point of view, because it can take quite a long time from the start of the process of carcinogenesis in the body to its clinical manifestations. It is statistically proven that the identification of tumor with relatively small dimensions (less than $1 \mathrm{~cm}$ ) in preclinical stage gives hope for a full recovery of the majority of patients $[3,4]$. That's why the primary task of the health care system is to promote the improvement of the quality of screening and the development of early diagnosis.
At the present time mammography is considered the main method of screening for breast cancer. Regular mammography screening can reduce mortality, especially in women of the age of 50 to 70 years, up to $30 \%$ [5]. The big advantage of mammography is the ability to detect microcalcifications that accompany breast cancer in about $30 \%$ of cases [6]. However, mammography has the age limit of use, and this investigation is generally recommended for breast examination in women over 40 years of age, mainly due to concerns about radiation exposure of mammary gland during mammography [7, 8], and recognition difficulties caused by increased density of the breast tissue $[9,10]$.

At the same time clinicians still do not have a clear concept about the methods that should be included in the 
screening of breast disorders in younger women [11]. Currently, the only officially recommended screening tests for women under 40 are breast self-examination and clinical breast examination at intervals of 1-2 years followed by ultrasound examination.

It is generally accepted that screening for early detection of breast cancer, which is performed with the standard technique of 12-24 months between tours, cannot always guarantee the detection of tumor at the early stage. This is especially true in case of young women, who are most often suffering from the rapid growth and aggressivity of breast cancer [12-14]. That is why we consider to be reasonable to complete the routine screening (at intervals of 12-24 months) with other non-invasive methods of breast examination.

The important task of diagnosis of the initial manifestations of pathological proliferation are imaging technology which make it possible to identify and differentiate changes present in breast tissue without adverse effect on a woman's body. Electrical impedance tomography represents one of such methods.

From as early as 1926, researchers have been studying the electrical properties of breast tumors [15]. While there have been varying results, the consensus is that electrical properties of breast tumors do differ from normal healthy tissue. It was found that breast cancer cells conduct electricity better than normal breast cells and tend to have lower electrical impedance [16-19].

Currently, due the latest scientific development is has become possible to create images of organs and tissue with the help of electrical impedance tomography. In contrast to other methods of visualization (X-ray, ultrasound examination, nuclear magnetic resonance, etc) EIT enables to examine first of all physiological state of organs and tissues, which is defined by biological process in the organism and is manifested by changes of electrical conductivity of organs and tissues. EIT allows to obtain images as well information about the state of organs, inclusive mammary glands in digital format (electrical conductivity, impedance, and histogram). The key advantages of the electrical impedance methods of diagnostics are: absolute safety of examination, high degree of self-descriptiveness, connected with considerable correlation of electro conductivity (electrical impedance) of biological tissues with their physical state, compactness and reasonable cost of the equipment, simplicity of the examination procedure [20]. The primary goal of this study was to evaluate the clinical efficiency of EIT and to analyze its possibilities to the differential diagnosis of pathologic lesions of the breast either solely, or in a combination with MMG/USG.

\section{Patients and methods}

Patients. Our study involved 870 eligible women with suspected pathological breast lesion discovered by mammography or ultrasound examination in St. Elisabeth Cancer Institute which were recommended to pass histological examination to verify the diagnosis. To conduct the study the approval from Institute review board was obtained. The study included the patients who accepted the additional examination of EIT after receiving materials about this new technique and signed the informed consent. All patients included in our study were divided into two age groups:

The $1^{\text {st }}$ group - patients older than 40 years (total of 724 patients)

The $2^{\text {nd }}$ group - patients younger than 40 years (total of 146 patients)

In the $1^{\text {st }}$ group we analyzed possibilities of EIT implementation to the differential diagnosis of pathologic lesions of the mammary gland (benign and malignant) either solely, or in a combination with mammography. In the $2^{\text {nd }}$ group we conducted the same analysis but with the ultrasound examination instead of mammography.

We excluded from this study patients who underwent surgery or biopsy of the mammary gland less than 3 months prior to the survey, or fine needle aspiration biopsy in less than one month prior to the survey, since the presence of a hematoma may mimic a false-positive result on the EIT. Also we excluded patients undergoing hormonal treatment or chemotherapy or radiotherapy. In addition, patients with implanted pacemakers were not involved into the study.

EIT imaging. The EIT examination was performed by means of the electrical impedance computer mammograph MEIK developed by the Institute of of Radio Engineering and Electronics, Russian academy of sciences. The examinations were performed in the supine position. Before current application, the examined breast was moistened by water. By means of one out of 256 electrodes of the matrix, weak alternative current $(0.5 \mathrm{~mA})$ with a frequency of $50 \mathrm{kHz}$ was applied to the inspected breast and subsequently the surface distribution of electric potentials were recorded and the signals were re-worked to electronic impedance images. After the completion of the reconstruction process appears seven images of the breast, corresponding to the seven scan planes. The first scanning plane corresponds to a depth of $0.4 \mathrm{~cm}$ from the surface of the skin, then every $0.8 \mathrm{~cm}$ in depth follow the rest 6 planes. In assessing of the electrical impedance for optimal visualization it is recommended to use average values from the $2 \mathrm{nd}$ scan level (depth $1.2 \mathrm{~cm}$ ), since given the anatomy of the breast, it is possible to find at this depth all its tissues and structures.

The electrical impedance image of a healthy mammary gland is characterized by mosaicism of the grey scale with smooth transition from darker colours to lighter ones, from low electrical conductivity to high, from hyperimpedance to hypoimpedance areas without focal inclusions (Figure 1). Normal mammary gland lobules are represented by isoimpedance areas of irregular shape with electrical conductivity $0.5 \pm 0.2$ conventional units located between connective tissue septa (Cooper's ligaments). Adipose tissue looks like hyperimpedance areas with conductivity below 0.3 (dark 


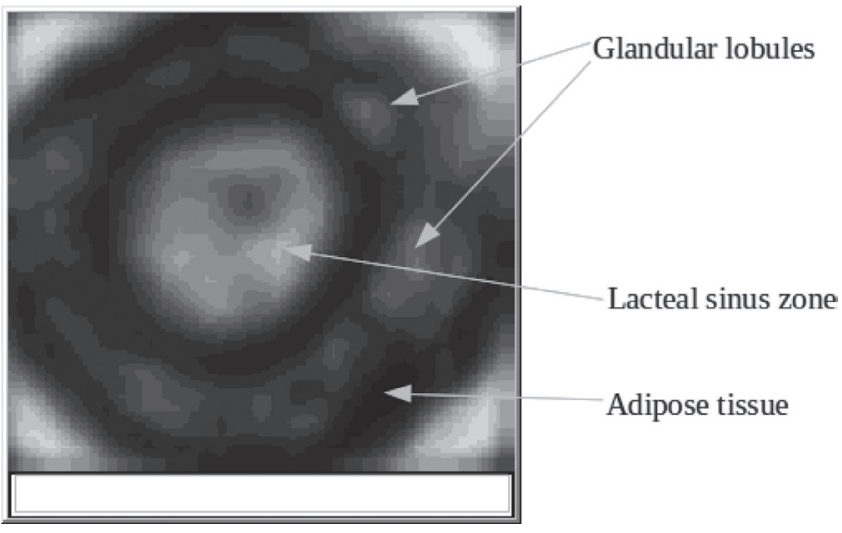

Figure 1. Electrical impedance tomogram of the normal mammary gland, the 2nd scan level (depth $1.2 \mathrm{~cm}$ )

Glandular lobules are presented as isoimpedance areas, lacteal sinus - as hypoimpedance area, adipose tissue - as hyperimpedance area.

gray), lacteal sinus is visualised as hypoimpedance area with the electrical conductivity above 0.7 conventional units (light gray). It is known that benign tumors develop from the tissue elements of an unaffected breast, hence there is no difference in electrical properties of tissue of a healthy breast and benign tumors. That's why benign tumors of small size (less than $1 \mathrm{~cm}$ ), as a rule, are not visualized on the electrical impedance tomograms. Benign lesions over $1 \mathrm{~cm}$, primarily cysts are shown as hyperimpedance areas with electrical conductivity below 0.95 conventional units. Fibroadenoma, usually appears as a roundish formation with some blurred contours with electrical conductivity 0.5 -0.65 conventional units starting from the second scan level (Figure 2). However, it should be noted that on EIT images the differential diagnosis of various benign tumors among themselves present a problem because the existing criteria for characteristics of the particular benign pathology in our opinion are unclear and insufficient. Therefore, we consider that the work of EIT is primarily aimed at characterization of the process with regard to its benignancy or malignancy. The focal changes in form of light hypoimpedance spots with electrical conductivity exceeding 0.95 conventional units, spanning multiple scanning planes indicate the probable location of the area of a malignant process. When using the optional contrasting, the areas of high conductivity are painted red. In most cases, in malignant tumors the tomograms revealed the deformation of contours, a violation of architectonics, displacement of internal structures of mammary gland (Figure 3 ).

Statistical analysis. Interpretation of the 3 diagnostic procedures (electrical impedance tomography, mammography and ultrasound examination) was compared with the histological examination with regard to sensitivity and specificity. The histological examination was considered the gold standard in our analysis.

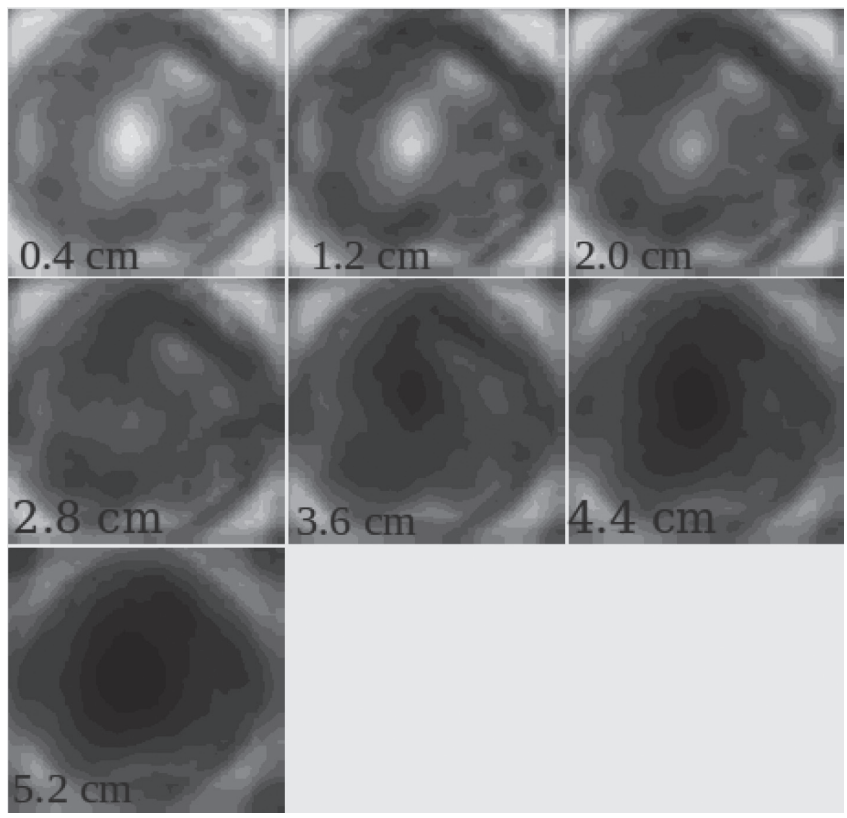

Figure 2. Electrical impedance tomogram of a 28 -year-old patient with fibroadenoma of the left mammary gland

The mammary gland structure correspond to the age norm. The hypoimpedance area ( 1 o'clock) is visualised on three scanning planes beginning from the first. The average electrical conductivity of this area was $\mathbf{0 . 6 2}$ conventional units. Cytologic examination - fibroadenoma.

Sensitivity and specificity were evaluated as follows:

$\%$ sensitivity $=[$ true positives $/($ true positives + false negatives) ] x 100;

$\%$ specificity $=[$ true negatives $/$ (true negatives + false positives)] x 100.

A result was classified as false-negative when a diagnostic method classified a histologically confirmed cancer as benign. A result was classified as false-positive when a diagnostic method classified a histologically confirmed benign lesion as cancer.

We compared the performance of all diagnostic methods individually and in combination using the results from all patients. We used the software Statgraphics Centurion for analysis average value, standard deviation and coefficient of variation of specificity (Table 1, Table 2) and the simple regression method for coefficient of correlation (Table 3 ).

\section{Results}

A total of 870 breast lesions were examine histologically, revealing the presence of 464 fibrocystic mastitis, 36 cysts, 123 fibroadenomas, 19 hyperplasias, 13 lipomas and 215 carcinomas. In the $1^{\text {st }}$ group (total of 724 patients) the distribution of particular pathologic lesions were as follows: 397 of fibrocystic mastitis (49.7\%), 27 cysts (3.4\%), 74 fibroadenomas (9.3\%), 15 hyperplasias (1.9\%), 11 lipomas (1.4\%) and 200 carcinomas 


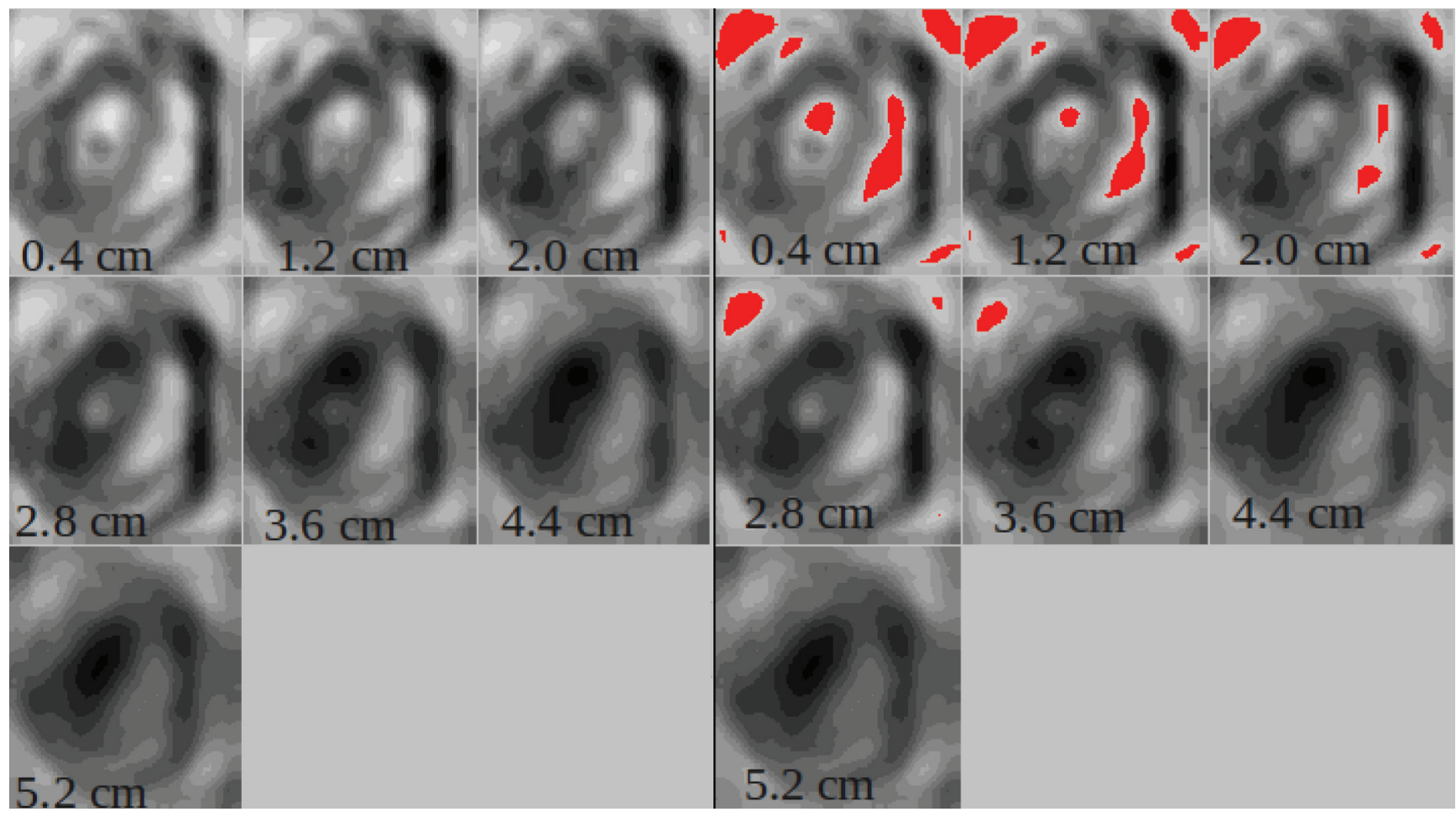

Figure 3. Electrical impedance tomogram of a 53-year-old patient with breast cancer of the left mammary gland

The mammary gland structure doesn't correspond to the age norm. An extensive hypoimpedance area (3 - 4 o'clock) of an irregular shape and electrical conductivity $>0.95$ conventional units can be observed on six scanning planes on the left tomogram. On the tomogram on the right the same area is highlighted red after using the function of optional contrasting.

(25\%). In the $2^{\text {nd }}$ group (total of 146 patients) the histological diagnosis were as follows: 67 of fibrocystic mastitis (34.3\%), 9 cysts (4.6\%), 49 fibroadenomas $(25.1 \%), 4$ hyperplasias $(2 \%)$, 2 lipomas (1\%), 15 carcinomas (7.7\%).
In Table 1. is presented the statistical analysis of the results of MMG and EIT in the $1^{\text {st }}$ group of patients.

The results showed that the average specificity of MMG was $79.5 \%$, of EIT - 76.6\%; in combination of MMG and

Table 1. Sensitivity and specificity of MMG, EIT and their combination in particular pathologies of the mammary gland in the $1^{\text {st }}$ group of patients.

\begin{tabular}{|c|c|c|c|c|c|c|c|c|c|c|c|c|}
\hline \multirow{3}{*}{$\begin{array}{l}\text { Histological } \\
\text { diagnosis }\end{array}$} & \multicolumn{4}{|c|}{ MMG } & \multicolumn{4}{|c|}{ EIT } & \multicolumn{4}{|c|}{ MMG+EIT } \\
\hline & \multirow{2}{*}{$\begin{array}{c}\text { Specificity } \\
\%\end{array}$} & \multicolumn{3}{|c|}{ Statistics ${ }^{\star}$} & \multirow{2}{*}{$\begin{array}{c}\text { Specificity } \\
\%\end{array}$} & \multicolumn{3}{|c|}{ Statistics $^{*}$} & \multirow{2}{*}{$\begin{array}{c}\text { Specificity } \\
\%\end{array}$} & \multicolumn{3}{|c|}{ Statistics ${ }^{*}$} \\
\hline & & $\begin{array}{c}\text { Average } \\
\%\end{array}$ & $\begin{array}{l}\text { Standard } \\
\text { deviation }\end{array}$ & $\begin{array}{l}\text { Coeff. of } \\
\text { variation }\end{array}$ & & $\begin{array}{c}\text { Average } \\
\%\end{array}$ & $\begin{array}{l}\text { Standard } \\
\text { deviation }\end{array}$ & $\begin{array}{l}\text { Coeff. of } \\
\text { variation }\end{array}$ & & $\begin{array}{c}\text { Average } \\
\%\end{array}$ & $\begin{array}{l}\text { Standard } \\
\text { deviation }\end{array}$ & $\begin{array}{l}\text { Coeff. of } \\
\text { variation }\end{array}$ \\
\hline Fibrocystic mastitis & 94.7 & & & & 85.4 & & & & 84.4 & & & \\
\hline Cysts & 80.0 & & & & 81.5 & & & & 74.1 & & & \\
\hline Fibroadenoma & 65.1 & & & & 67.6 & & & & 66.2 & & & \\
\hline - with proliferation & 40.0 & 79.5 & 10.5 & 13.2 & 38.5 & 76.6 & 8.8 & 11.4 & 38.5 & 72.8 & 7.4 & 10.1 \\
\hline - non-proliferative & 68.4 & & & & 73.8 & & & & 72.1 & & & \\
\hline Hyperplazia & 77.8 & & & & 66.7 & & & & 66.7 & & & \\
\hline \multirow[t]{3}{*}{ Lipoma } & 80.0 & & & & 81.8 & & & & 72.7 & & & \\
\hline & Sensitivity & & & & Sensitivity & & & & Sensitivity & & & \\
\hline & $\%$ & & & & $\%$ & & & & $\%$ & & & \\
\hline Carcinoma & 87.8 & & & & 86.0 & & & & 94.5 & & & \\
\hline
\end{tabular}

* The data from subcategory fibroadenoma with proliferation and fibroadenoma without proliferation were not included in the calculation of the average value, standard deviation and coeff. of variation because these are not the self-diagnosis but form the part of the diagnosis "fibroadenoma"; MMG - mammography, EIT - electrical impedance tomography, coeff. of variation - coefficient of variation. 
EIT $-72.8 \%$. The maximum spread of specificity data was observed in MMG ( coeff. of variation - 13.2\% ), the minimum - in combination of MMG and EIT ( coeff. of variation $-10.1 \%)$.

Analyzing the particular pathologies we noted that the specificity of MMG compared with EIT was higher in the following pathological lesions: fibrocystic mastopathy $(94.7 \%$ vs. $85.4 \%)$ and hyperplasia $(77.8 \%$ vs. $66.7 \%)$.

The specificity of EIT in fibroadenoma was higher than of MMG (67.6\% vs. $65.1 \%)$. It is to emphasize that we divided the diagnosis of "fibroadenoma" into 2 subcategories: fibroadenoma with proliferation and non-proliferative fibroadenoma. In the subcategory non-proliferative fibroadenoma the specificity of EIT was higher than that of mammography ( $73.8 \%$ vs. $68.4 \%)$. However, EIT in case of fibroadenoma with proliferation revealed a large number of false-positive results, which significantly reduced the overall specificity of the method in the diagnosis of fibroadenoma. Such a number of false-positive results, in our opinion, is due to the fact that the work of the EIT is associated mainly with the assessment of the metabolic processes taking place in the body and in a less degree the results are influenced by the anatomy of the organ. Therefore the pathology associated with increased cell proliferation can be interpreted on EIT as a malignancy and the patient must be listed in the risk group. The high specificity of EIT in case of breast cysts in our opinion is conditioned upon the fact that the cyst is filled with fluid, and the fluid is well known for a high electrical conductivity, that's why it is well displayed on the EIT images. When using EIT in combination with mammography the specificity for all pathological lesions slightly decreased or remained at the same level.

The difference in rates of the sensitivity of both, MMG and EIT in breast cancer was small: $87.8 \%$ for MMG and $86 \%$ for the EIT. However, the sensitivity of the combination of these methods increased to $94.5 \%$.

In Table 2. are presented the statistical analysis of the results of USG and EIT in the $2^{\text {nd }}$ group of patients.

The results showed that in young women the average specificity of USG was $90.2 \%$, of EIT $-89.2 \%$; in combination of USG and EIT $-86.4 \%$. The maximum spread of specificity data was observed in USG ( coeff. of variation - $14.1 \%$ ), the minimum - in EIT ( coeff. of variation - $10.1 \%$ ). The specificity of USG compared to EIT was higher in fibrocystic mastopathy $(98.5 \%$ vs. $92.5 \%)$ and cysts ( $100 \%$ vs. $88.9 \%)$.

EIT showed higher specificity for fibroadenomas $(89.8 \%$ vs. $77.6 \%)$. However, similarly as in the first group of patients, a large number of false-positive results on EIT were found in subcategory fibroadenoma with proliferation, therefore the specificity of the USG in this subcategory was higher $(77.8 \%$ vs. $66.7 \%$ ). The specificity of both methods was similar in case of hyperplasia (75\%) and lipoma (100\%). But considering the small number of patients involved into this group (total of 4 patients with hyperplasia and 2 patients with lipoma), conclusions on these pathologies may be unreliable. The specificity of the combined use of the EIT with USG was either unchanged or decreased.

As for breast cancer, as compared to EIT, the sensitivity of USG was significantly higher ( $86.7 \%$ vs. $66.7 \%)$, however, the combination of these two methods increased the sensitivity right up to $93.3 \%$.

In addition, we also analyzed all false-negative results on the EIT (Table 3).

Analysis of false-negative results depending on the stage of the process has shown that as the earlier stage of the disease and as the smaller the dimensions of the tumor, the higher is the number of false-negative results. Since the P-value is less than 0.05 , there is a statistically significant relationship

Table 2. Sensitivity and specificity of USG, EIT and their combination in particular pathologies of the mammary gland in the $2^{\text {nd }}$ group of patients.

\begin{tabular}{|c|c|c|c|c|c|c|c|c|c|c|c|c|}
\hline \multirow{3}{*}{$\begin{array}{l}\text { Histological } \\
\text { diagnosis }\end{array}$} & \multicolumn{4}{|c|}{ USG } & \multicolumn{4}{|c|}{ EIT } & \multicolumn{4}{|c|}{ USG+EIT } \\
\hline & \multirow{2}{*}{$\begin{array}{c}\text { Specificity } \\
\%\end{array}$} & \multicolumn{3}{|c|}{ Statistics ${ }^{\star}$} & \multirow{2}{*}{$\begin{array}{c}\text { Specificity } \\
\%\end{array}$} & \multicolumn{3}{|c|}{ Statistics ${ }^{\star}$} & \multirow{2}{*}{$\begin{array}{c}\text { Specificity } \\
\%\end{array}$} & \multicolumn{3}{|c|}{ Statistics $^{*}$} \\
\hline & & $\begin{array}{c}\text { Average } \\
\%\end{array}$ & $\begin{array}{l}\text { Standard } \\
\text { deviation }\end{array}$ & $\begin{array}{r}\text { Coeff. of } \\
\text { variation }\end{array}$ & & $\begin{array}{c}\text { Average } \\
\%\end{array}$ & $\begin{array}{l}\text { Standard } \\
\text { deviation }\end{array}$ & $\begin{array}{l}\text { Coeff. of } \\
\text { variation }\end{array}$ & & $\begin{array}{c}\text { Average } \\
\%\end{array}$ & $\begin{array}{l}\text { Standard } \\
\text { deviation }\end{array}$ & $\begin{array}{l}\text { Coeff. of } \\
\text { variation }\end{array}$ \\
\hline Fibrocystic mastitis & 98.5 & 90.2 & 12.8 & 14.1 & 92.5 & 89.2 & 9.0 & 10.1 & 92.5 & 86.4 & 10.9 & 12.6 \\
\hline Cysts & 100.0 & & & & 88.9 & & & & 88.9 & & & \\
\hline Fibroadenoma & 77.6 & & & & 89.8 & & & & 75.5 & & & \\
\hline -with proliferation & 77.8 & & & & 66.7 & & & & 77.8 & & & \\
\hline -non-proliferative & 77.5 & & & & 95.0 & & & & 75.0 & & & \\
\hline Hyperplazia & 75.0 & & & & 75.0 & & & & 75.0 & & & \\
\hline Lipoma & 100.0 & & & & 100.0 & & & & 100.0 & & & \\
\hline & Sensitivity & & & & Sensitivity & & & & Sensitivity & & & \\
\hline & $\%$ & & & & $\%$ & & & & $\%$ & & & \\
\hline Carcinoma & 86.7 & & & & 66.7 & & & & 93.3 & & & \\
\hline
\end{tabular}

* The data from subcategory fibroadenoma with proliferation and fibroadenoma without proliferation were not included in the calculation of the average value, standard deviation and coeff. of variation because these are not the self-diagnosis but form the part of the diagnosis "fibroadenoma"; USG - ultrasound examination. 
between percentage of $\mathrm{FN}$ results and stage of the cancer at the $95.0 \%$ confidence level. The correlation coefficient equals -0.95 , indicating a relatively strong relationship between these variables.

In addition, we analyzed the dependence of the false-negative results in relation to the tumor grade. The calculations have shown that the P-value is less than 0.05 and the correlation coefficient equals -0.99 , ie similarly defined strong relationship between those 2 parameters. This again confirms the fact that the EIT is more sensitive in the processes that are accompanied by increased proliferation.

Furthermore, in one particular patient of 67 years old involved in our study, the screening mammography revealed benign changes in the breast, but on the EIT the signs of malignancy were noted. Histological examination brought negative outcome, so the result of the EIT has been considered as a falsepositive. However, after 1 year, the patient was diagnosed with cancer of the breast in a stage T1N1M0.

\section{Discussion}

The main goal of breast cancer screening is to detect disease at an early stage and to reduce mortality of the population. Randomized clinical trials have demonstrated that mammography used as a screening tool in women older than 49 years can reduce mortality from breast cancer by 30 per cent [5].

For young women under 40 years of age clear recommendations for screening program is still missing. Statistically, it is estimated that one of 249 women aged $30-40$ years will have the diagnosis of breast cancer [20]. Breast cancer is the leading cause of death from cancer in young women (15-40 years) [21] having more aggressive evolution and progression in young age.

Currently, screening in women younger than 40 years is represented mostly by self-examination and clinical palpation followed by ultrasound examination. The scientists still debate about the need to include ultrasound examination of breast in the screening program in young women, and the US Food and Drug Administration (FDA) still did not recommend this method for mass screening for breast cancer.

The American Cancer Society is recommending a screening breast MRI for young women with a 20 to $25 \%$ life-time risk of breast cancer including women with family history of breast cancer and those who have received chest radiation for Hodgkin's lymphoma [22]. However the massive use of MRI cannot be implemented because of the high cost and less accessibility.

Mammography, ultrasound examination, MRI give us a conception about the structural changes in the breast - about the size and shape of mass lesion, its exact location, about the presence of microcalcifications, etc. Electrical impedance tomography gives the physician additional information about the physiological processes taking place in the breast, about the presence of metabolic abnormalities including disorders of the electrical conductivity of cells and tissues. This infor-
Table 3. The analysis of false-negative results of the EIT depending on the stage of the process and tumor grade.

\begin{tabular}{lcccc}
\hline $\begin{array}{l}\text { Cancer } \\
\text { caracteristics }\end{array}$ & Total & $\begin{array}{c}\text { Number of FN* } \\
\text { results of EIT }\end{array}$ & $\begin{array}{c}\text { Statistics } \\
\text { Correlation } \\
\text { Coefficient }\end{array}$ & P-Value \\
\hline Stage & 22 & $5(22.7 \%)$ & -0.95 & 0.0115 \\
Tis & 114 & $18(15.8 \%)$ & & \\
T0-1 & 64 & $9(14.1 \%)$ & & \\
T2 & 9 & $1(11.1 \%)$ & & \\
T3 & 6 & 0 & & \\
T4 & & & & \\
Grading & 96 & $17(17.7 \%)$ & -0.99 & \\
G1 & 78 & $12(15.4 \%)$ & & \\
G2 & 31 & $4(12.9 \%)$ & & \\
G3 & & & & \\
\hline
\end{tabular}

${ }^{*} \mathrm{FN}$ - false negative

mation can be very valuable, especially in the period between screenings, which can last from 12 to 24 months, ie fairly long period of time.

It is known that the proportion of breast cancer cases, which are diagnosed in the period between screenings (the so-called interval cancers), represents a measure of screening efficiency. Studies in different countries have shown that the risk of undetected cancer occurrence related to intervals between breast examination is relatively high [23-26].

Currently, there is a high demand for non-irradiating, easyto-use methods of investigation, which could be used between the rounds of screening, including in young women, in order to detect breast cancer at an earlier stage. Electrical impedance tomography represents one of such methods.

The possibilities of EIT were analyzed by many scientists. A very early study by Piperno and colleagues [27] was performed with the device "Mammoscan". From 6000 examined patients 745 underwent biopsy. Besides EIT examination all patients underwent thermography, ultrasound examination, mammography and diaphanoscopy. In 9 cases, EIT identified malignancy where other tests provided negative results. Furthermore, in 5 cases, EIT clarified ambiguous findings and identified cancer.

Melloul et al. [28] analyzed the possibilities of $99 \mathrm{mTc}$ sestamibi scintimammography (SMM) and of the electrical impedance mammograph TransScan TS2000 as adjunct modalities. In this study the TransScan TS2000 showed the ability to detect small lesions. The smallest lesion detected by the TransScan TS2000 was $3 \mathrm{~mm}$ in diameter. The sensitivity of the TransScan TS2000 was found to be $72.2 \%$ and the specificity was $67 \%$.

Malich et al. [29] also presented a study where the capability of the TransScan TS2000 to detect breast cancer was evaluated. The author concluded that EIT can be a valuable adjunct to MMG and USG in the assessment of breast lesions. In the year 2001, a more comprehensive study of Malich et al. [30] was performed. The survey included 240 histologically proven 
breast lesions. The results showed that the addition of EIT to MMG and USG increased the sensitivity from $86.4 \%$ to $95.1 \%$, but the accuracy decreased from $82.3 \%$ to $75.7 \%$.

In the study of Stojadinovic et al. 1103 women younger than 40 years were eligible for EIT examination with T-Scan 2000ED. The EIT sensitivity and specificity for this group of patients was $50 \%$ and $90 \%$, respectively. The author concluded that this method looks promising for early detection of breast cancer and to identify young women at increased risk of breast cancer [31].

In our study we demonstrated that the difference in parameters of sensitivity of mammography and EIT in breast cancer was small: $87.8 \%$ for mammography and $86 \%$ for the EIT. Moreover, the combination of these methods increased the sensitivity to 94.5\%. Similar situation was observed in young women: the sensitivity of ultrasound examination was higher than that of the EIT ( $86.7 \%$ vs. $66.7 \%$ ), however, the combination of these two methods increased the sensitivity right up to $93.3 \%$. This suggests that the use of EIT in addition to MMG/USG in screening for breast cancer is a reasonable and have a great impact onto early detection and follow-up of breast cancer.

It is also known that frequent repeated check-ups may lead to the development of psychosocial morbidity accompanied with emotional, cognitive and functional disorders resulted from long-term uncertainty and repeatedly evoked fear from cancer detection and progression having negative impact onto patient's quality of life $[27,28]$. Since EIT is less aggressive than mammography (breast compression, pressure, pain) [29, 30], its implementation in the long run is beneficial in evoking less negative emotions in examined patients.

The goal of our study was not only to assess the ability of EIT to detect breast cancer, but also to confirm EIT efficiency in the selection of patients who are at high risk of breast cancer and require comprehensive investigation in specialized institutions. This group includes patients with diseases that are accompanied by active proliferation (e.g., fibroadenoma with proliferation or proliferative mastopathy).

For diagnosis of benign pathological disorders the EIT was less effective than the mammography or ultrasound examination. A large number of false-positive results can be attributed to inflammatory, metabolic, and cellular, rather than structural changes. It is to emphasize that preclinical changes in cell metabolism, which may be indicators of incipient carcinogenesis, always precede anatomical changes observed with mammography or remain to be an ultrasound examination. This fact was confirmed in our study, when in one patient with negative mammography and positive EIT, breast cancer was confirmed one year after the initial examination.

Analyzing the false-negative results obtained on EIT we observed the dependence of the sensitivity of the method on the stage of the process. We consider this is due to the particularity of the EIT unit: it makes tomographic slices at a distance of 8 $\mathrm{mm}$ from each other and the tumor with size of 5-8 $\mathrm{mm}$ can be missed. In contrary, EIT showed a higher sensitivity in tumor grade G3, which also confirms the fact that the method re- sponds well to more advanced proliferative processes. Despite the evident effectiveness of EIT examination, EIT remains to be an auxiliary method and not a substitute for mammography or ultrasound examination. EIT in combination with these methods of investigation can demonstrate good performance and therefore deserves more attention.

\section{Conclusions}

Taking in consideration the above, we recommend the use of electrical impedance tomography in women of all ages (but especially in younger women) between the rounds of screening to reduce the risk of interval cancers, and to identify patients who are at high risk and require comprehensive investigation in specialized institutions. The use of EIT is also advisable in cases where ultrasound examination and mammography cannot give a definite answer about the nature of mass lesion, as well as in cases of monitoring of treatment progress in hormone therapy, chemotherapy or radiotherapy.

We consider that the widespread use of EIT diagnostic method will help to increase the rate of early detection of breast cancer with minimal economic resources and highly qualified staff time expenditures.

Our study does not dispute the fact that the EIT is an auxiliary method and not a substitute for mammography or ultrasound examination, because it does not provide information about the structural changes in the organ. But EIT in combination with these methods of investigation can demonstrate good performance and therefore deserves more attention.

\section{References}

[1] ONDRUSOVA M, MUZIK J, DURDIK S, ONDRUS D. Long-term trends in the development of the epidemiology of breast cancer in the Slovak and Czech Republic with reference to applied screening and international comparisons. Neoplasma 2012; 59: 70-8. http: //dx.doi.org/10.4149/ neo $2012 \quad 009$

[2] DE SANTIS C, SIEGEL R, BANDI P, JEMAL A. Breast Cancer Statistics, 2011. CA Cancer J Clin 2011; 61: 409-418.

[3] FRIEDENBERG RM. The 21st century: the age of screening Radiology. Radiology 2002; 23: 1-4. http: //dx.doi. org/10.1148/radiol.2231011680

[4] DUIJM LEM, GROENEWOUD JH, HENDRIKS JHCL, DE KONING HJ. Independent Double Reading of Screening Mammograms in the Netherlands: Effect of Arbitration Following Reader Disagreements. Radiology 2004; 231: 564. http: //dx.doi.org/10.1148/radiol.2312030665

[5] BELLA V. Mammography - importance, possibilities, current screening situation of the breast cancer and further expansion possibilities. Onkologia (Bratisl.) 2006; 1: 26-28 (In Slovak).

[6] LEHOTSKA V, PRIKAZSKA M. Mammography - importance, possibilities, technical trends, current situation and perspective. Onkologia (Bratisl.) 2006; 1: 19-21(In Slovak). 
[7] JUNG H: Assessment of usefulness and risk of mammographic screening with exclusive to radiation risk. Radiologe 2001; 41: 385-395. http: //dx.doi.org/10.1007/s001170051018

[8] BEEMSTERBOER PM, WARMERDAM PG, BOER R, DE KONING HJ. Radiation risk of mammography related to benefit in screening programmes: A favourable balance? J Med Screen 1998; 5: 81-87. http: //dx.doi.org/10.1136/jms.5.2.81

[9] GOERGEN SK: Characteristics of breast carcinomas missed by screening radiologists. Radiology 1997; 204: 131-135.

[10] MA L, FISHELL E, WRIGHT B, HANNA W, ALLAN S et al. Case control study of factors associated with failure to detect breast cancer by mammography. J Natl Cancer Inst 84: 781-785, 1992. http: //dx.doi.org/10.1093/jnci/84.10.781

[11] OVERMOYER B: Breast cancer screening. Med Clin N Am 1999; 83: 1443-1466. http: //dx.doi.org/10.1016/S00257125(05)70174-7

[12] FISHER CJ, EGAN MK, SMITH P, WICKS K, MILLIS RR et al. Histopathology of breast cancer in relation to age. Br J Cancer 1997; 75: 593-596. http: //dx.doi.org/10.1038/bjc.1997.103

[13] YILDIRIM E, DALGIC T, BERBEROGLU. Prognostic significance of young age in breast cancer. J Surg Oncol 2000; 74: 267-272. http: //dx.doi.org/10.1002/1096-9098(200008)74: 4<267: : AID-ISO5>3.0.CO; 2-N

[14] XIONG Q, VALERO V, KAU V, KAU SW, TAYLOR S et al. Female patients with breast carcinoma age 30 years and younger have a poor prognosis: The M.D. Anderson Cancer Center experience. Cancer 2001; 92: 2523-2528. http: //dx.doi.org/10.1002/1097-0142(20011115)92: $10<2523:$ : AID-CNCR1603>3.0.CO;2-6

[15] FRICKE H, MORSE S. The electric capacity of tumors in the breast. J Cancer Res 1926; 16: 340-376.

[16] SUROWIEC A, STUCHLY S, BARR R, SWARUP A. Dielectric properties of breast carcinoma and the surrounding tissues. IEEE Trans Biomed Eng 1988; 35: 257-263. http: //dx.doi. org/10.1109/10.1374

[17] JOSSINET J. The impedivity of freshly excised human breast tissue. Physiol Meas 1998; 19: 61-75. http: //dx.doi. org/10.1088/0967-3334/19/1/006

[18] SINGH B, SMITH CW, HUGHES R. In vivo dielectric spectrometer. Med Biol Comput 1979; 17: 45-60. http: //dx.doi. org/10.1007/BF02440953

[19] JOSSINET J. Variability of impedivity in normal and pathological breast tissue. Med Biol Eng Comput 1996; 34: 346-350. http: //dx.doi.org/10.1007/BF02520002

[20] TYNA A HOPE, SIAN E ILES. Technology review: The use of electrical impedance scanning in the detection of breast cancer. Breast Cancer Res 2004; 6: 69-74. http: //dx.doi. org $/ 10.1186 /$ bcr 888

[21] American Cancer Society: Breast Cancer Facts and Figures 20012002. Department of Epidemiology and Surveillance Research, American Cancer Society, Atlanta, GA, 2003, pp 1-23

[22] PEER PG, VERBEEK AL, MRAVUNAC M, HENDRIKS JH, HOLLAND R. Prognosis of younger and older patients with early breast cancer. Br J Cancer 1996; 73: 382-385. http: /dx.doi.org/10.1038/bjc.1996.65

[23] Cancerscreening.nhs.uk [homepage on the Internet]. NHS Cancer Screening Programmes. Screening for Breast Can- cer in England: Past and Future. NHSBSP Publication No 61; c2006-02 [updated 2006 February; cited 2011 Aug 9]. Available from: http: //www.cancerscreening.nhs.uk/breastscreen/publications/nhsbsp61.html.

[24] SHAPIRO S. Evidence on screening for breast cancer from a randomized trial. Cancer 1977; 39: 2772-2782. http: // dx.doi.org/10.1002/1097-0142(197706)39: 6<2772: : AIDCNCR2820390665>3.0.CO; $2-\mathrm{K}$

[25] FRISELL J, GLAS U, HELLSTROM L, SOMELL A. Randomized mammographic screening for breast cancer in Stockholm. Breast Cancer Res Treat 1986; 8: 45-54. http: //dx.doi.org/10.1007/BF01805924

[26] FRISELL J, EKLUND G, HELLSTROM L, SOMELL A. Analysis of interval breast carcinomas in a randomized screening trial in Stockholm. Breast Cancer Res Treat 1987; 9: 219-225. http: //dx.doi.org/10.1007/BF01806383

[27] TABAR L, FAGERBERG G, DUFFY SW, DAY NE, GAD A. Update of the Swedish two-county program of mammographic screening for breast cancer. Radiol Clin North Am 1992; 30: 187-210.

[28] PIPERNO G, FREI EH, MOSHITZKY M. Breast cancer screening by impedance measurements. Frontiers Med Biol Eng 1990; 2: 111-117.

[29] MELLOUl M, PAZ A, OHANA G, LAVER O, MICHALEVICH D. Double phase Tc-sectamibi scintimammography and Trans-Scan in diagnosing breast cancer. J Nucl Med 1999; 40: 376-380.

[30] MALICH A, FRITSCH T, ANDERSON R, BOEHM T, FREESMEYER MG. Electrical impedance scanning for classifying suspicious lesions: first results. Eur Radiol 2000; 10: 1555-1561. http: //dx.doi.org/10.1007/s003300000553

[31] MALICH A, BOHM T, FACIUS M, FREESSMEYER M, FLECK M. Additional value of electrical impedance scanning: experience of 240 histologically-proven breast lesions. Eur J Cancer 2001; 37: 2324-2330. http: //dx.doi.org/10.1016/ S0959-8049(01)00283-0

[32] STOJADINOVIC A, NISSAN A, GALLIMIDI Z, LENINGTON S, LOGAN W. Electrical Impedance Scanning for the Early Detection of Breast Cancer in Young Women: Preliminary Results of a Multicenter Prospective Clinical Trial. J Clin Oncol 2005; 23: 2703-2715. http: //dx.doi.org/10.1200//CO.2005.06.155

[33] BENCOVA V, SVEC J, BELLA V. The role of psychosocial oncology in the health care of breast cancer survivors. Bratisl Med J 2009; $110:$ 374-375.

[34] BENCOVA V, MRAZOVA A, SVEC J. Psychosocial morbidity - an unfilled gap in the undergraduate courses of medicine and nursing. Clin Social Work 2010; 1-2: 38-42.

[35] ARMSTRONG K, MOYE E, WILLIAMS S, BERLIN JA, REYNOLDS EE et al. Screening mammography in women 40 to 49 years of age: a systematic review for the American College of Physicians. Ann Intern Med 2007; 146 : 516-526. http: //dx.doi.org/10.7326/0003-4819-146-7-200704030-00008

[36] METTLER FA, UPTON AC, KELSEY CA, ASHBY RN, ROSENBERG RD et al. Benefits versus risks from mammography: a critical reassessment. Cancer 1996; 77 : 903-909. http: //dx.doi.org/10.1002/(SICI)1097-0142(19960301)77: 5<903: : AID-CNCR15>3.0.CO; 2-7 